\title{
Reduced expression of odd-skipped related transcription factor 1 promotes proliferation and invasion of breast cancer cells and indicates poor patient prognosis
}

\author{
YUAN WANG ${ }^{1,2^{*}}$, LEI LEI ${ }^{2^{*}},{\text { FANG } \mathrm{XU}^{3^{*}} \text { and HONG-TAO XU }}^{2}$ \\ ${ }^{1}$ Department of Pathology, Jinzhou Medical University, Jinzhou, Liaoning 121001; ${ }^{2}$ Department of Pathology, \\ The First Hospital and College of Basic Medical Sciences of China Medical University, Shenyang, Liaoning 110001; \\ ${ }^{3}$ Department of Orthopaedics, Jinzhou Second Hospital, Jinzhou, Liaoning 121000, P.R. China
}

Received January 6, 2020; Accepted June 17, 2020

DOI: $10.3892 / \mathrm{ol} .2020 .11820$

\begin{abstract}
Odd-skipped related transcription factor 1 (OSR1) serves an important role in the development of the intermediate mesoderm; however, its expression in cancer remains unknown. The present study aimed to explore the expression and role of OSR 1 in breast cancer development. Immunohistochemistry was performed to detect OSR1 expression in breast cancer tissue and western blot analysis was used to evaluate the expression of OSR 1 and related proteins, including $\beta$-catenin, c-Myc and cyclin D1. OSR1 expression was increased following transfection of MCF7 cells with OSR1 overexpression vector (MCF7-OSRI) and reduced by transfecting MDA-MB-231 cells with small interfering (si)RNA targeting OSR1 (MDA-MB-231-siOSR1). Cell proliferation and Matrigel ${ }^{\mathrm{TM}}$ invasion assays were used to investigate the effects of OSR1 on the proliferation and invasion of breast cancer cells. OSR1 was downregulated in breast cancer tissue compared with that in normal breast tissue and associated with lymph node metastases and estrogen receptor (ER) expression. Furthermore, reduced expression of OSR1 was associated with poor patient prognosis. Overexpression of OSR1 inhibited the proliferation and invasion of breast cancer cells. Western blot analysis of MCF7-OSR1 cells demonstrated that compared with that in the control cells, the expression of E-cadherin was increased, whereas that of key epithelial-mesenchymal transition (EMT) proteins, N-cadherin and Snail, was
\end{abstract}

Correspondence to: Professor Hong-Tao Xu, Department of Pathology, The First Hospital and College of Basic Medical Sciences of China Medical University, 77 Puhe Road, Shenyang, Liaoning 110001, P.R. China

E-mail: xuht@cmu.edu.cn

${ }^{*}$ Contributed equally

Key words: odd-skipped related transcription factor 1, breast cancer, Wnt signaling pathway, epithelial-mesenchymal transition process decreased. In addition, overexpression of OSR1 significantly decreased the expression level of $\beta$-catenin and Wnt target genes, such as c-Myc and cyclin D1, compared with that in the control cells. These expression patterns were reversed in the MDA-MB-231-siOSR1 cells. The results of the present study suggested that OSR1 downregulates the activity of the Wnt signaling pathway and EMT, which inhibits the proliferative and invasive abilities of breast cancer cells.

\section{Introduction}

Breast cancer is one of the most common malignant tumors in the world and the leading cause of cancer-associated death in women in recent years $(1,2)$. Numerous complex factors are involved in the proliferation and invasion of tumor cells, including human epidermal growth factor receptor 2 (HER-2), androgen receptor and estrogen receptor (ER) (3-6). In previous years, significant advances have been made in discerning the molecular drivers of breast cancer and characterizing distinct subtypes based on gene expression profiles (1).

The odd-skipped related transcription factor 1 (OSRI) gene belongs to the OSR family; it is located on human chromosome 2 (2p24.1) and encodes a 266-amino acid protein with three $\mathrm{C} 2 \mathrm{H} 2$-type zinc fingers (7). OSR1 has multiple functions and is essential for the development of the intermediate mesoderm. This process is strictly regulated and is influenced by OSR1 in a number of ways (8-17). Bone morphogenetic protein (BMP) (8), retinoic acid (9), and 1,25-dihydroxyvitamin D3 (10) have been found to activate OSR1, whereas IKAROS family zinc finger 1 (IKZF1) and RUNX family transcription factor 2 (RUNX2) represses it (11). OSR1 suppresses the nodal signaling pathway and SOX9 mRNA expression $(12,13)$. OSR 1 also serves important roles in embryonic urogenital formation, heart formation, and tongue development (13-17). Zhang et al (18) demonstrated that OSR1 was downregulated in renal cell carcinoma (RCC) cells through promoter methylation. In addition, depletion of OSR1 by small interfering (si)RNA repressed the expression level of several tumor suppressor genes involved in the p53 pathway, such as p53, p21, p27, p57 and RB, and suppressed the transcriptional activity of p53 in RCC (18). Furthermore, 
expression of OSR1 inhibited the invasion and proliferation abilities of RCC cells (18). Otani et al (19) demonstrated that OSR1 was commonly downregulated by siRNA by promoter methylation in gastric cancer. In addition, expression of OSR1 was demonstrated to inhibit gastric cancer cell growth, arrest the cell cycle and induce cell apoptosis (19). The role and underlying mechanism of OSR1 in other types of cancer, apart from renal and gastric cancer has not been well characterized. It was reported that OSR1-mediated tumor suppression in gastric cancer occurs by repression of the $\mathrm{Wnt} / \beta$-catenin signaling pathway and the activation of p53 pathway (19). The Wnt signaling pathway is regulated by multiple proteins, among which, $\beta$-catenin serves a key role (20). Accumulation of $\beta$-catenin in the cytoplasm and nucleus activates target genes of the Wnt pathway, such as cyclin D1 and c-Myc (21). Activation by $\beta$-catenin causes carcinogenesis and tumor progression in numerous types of cancer, such as lung, gastric and intestine cancers (21). Overall, the expression and function of OSR1 in breast cancer remains unclear.

In the present study, the expression of OSR 1 in breast cancer and corresponding normal adjacent tissues, and its association with clinicopathological factors was examined. In addition, the effects of OSR 1 on the proliferative and invasive abilities of breast cancer cells was investigated, as well as identifying the regulating effects of OSR1 on the epithelial-mesenchymal transition (EMT) process and activation of the Wnt signaling pathway in breast cancer cells.

\section{Materials and methods}

Patient data and tissue specimens. Tissue samples from 70 female patients with breast cancer who underwent complete surgical resection at the First Affiliated Hospital of China Medical University between September 2013 and August 2016 were selected from the archival files in the Department of Pathology. The 70 breast cancer samples were accompanied by adjacent normal breast tissue specimens. and were located $>2 \mathrm{~cm}$ away from the tumor. The mean age of the patients was 50 -years-old (range, 31 to 70 years). The patients were graded according to WHO (22) and TNM staging systems (23), and divided into ER, PR and HER2 positive and negative expression groups. The histological grades of the specimens were evaluated as grade I $(n=18)$, II $(n=44)$ and III $(n=8)$. And patients were categorized into stage I $(n=32)$, II $(n=21)$ or III $(n=17)$. Lymph node metastases were found in 30 cases. Estrogen receptor (ER)-, progesterone receptor (PR)- and human epidermal growth factor receptor 2 (HER2)-positive expression was found in 45,43 and 24 cases, respectively. A total of 20 pairs of fresh tumor and corresponding normal tissue specimens were collected following resection between September 2013 and August 2016 and immediately stored at $-80^{\circ} \mathrm{C}$ for subsequent use. The study was conducted in accordance with the Declaration of Helsinki and approved by the Institutional Review Board of the First Hospital and College of Basic Medical Sciences of China Medical University, China [approval no. LS(2018)016]. All patients provided written informed consent.

The Cancer Genome Atlas (TCGA) data collection and analysis. The mRNA expression data of OSR1 in breast cancer and adjacent normal breast tissue was analyzed and downloaded directly from the online database, UALCAN (http://ualcan. path.uab.edu) (24). The association between OSR1 expression and prognosis of breast cancer was analyzed and downloaded directly from the online database, The Human Protein Atlas (https://www.proteinatlas.org/) (25), which is based on TCGA.

Immunohistochemistry. After fixation in $10 \%$ neutral formalin at room temperature for $24 \mathrm{~h}$, all resected specimens were embedded in paraffin and cut into 4- $\mu \mathrm{m}$ sections. Immunostaining was performed using a streptavidin-peroxidase method. All sections were deparaffinized, rehydrated, and heated in $0.01 \mathrm{M}$ citrate buffer for $2.5 \mathrm{~min}$ at $100^{\circ} \mathrm{C}$ in an autoclave. Then, the sections were incubated with anti-OSR1 rabbit polyclonal antibody (cat. no. ab179612; 1:100; Abcam) and anti-ER mouse monoclonal antibody (cat. no. MAB-0062; 1:200; Fuzhou Maixin Biotech Co.) overnight at $4^{\circ} \mathrm{C}$. Subsequently, the sections were incubated with the secondary antibody and horseradish peroxidase-conjugated streptavidin-biotin at $37^{\circ} \mathrm{C}$ for $2 \mathrm{~h}$ (cat.no. KIT 9002; Fuzhou Maixin Biotech Co., Ltd.). Expression was visualized using 3,3'-diaminobenzidine chromogen (Fuzhou Maixin Biotech Co., Ltd.), as previously described (26).

A total of 2 investigators, who were blinded to the clinical data, evaluated the sections, using 5 fields of view randomly per slide and 100 cells per view were observed at x400 magnification using light microscope (Olympus Corporation). The positive rate for each case was calculated from the percentage of positively stained cells and scored as follows: 1, 1-25; 2, 26-50; 3, 51-75; and 4, 76-100\%. The intensity of immunostaining was scored as $0,1,2$, or 3 , for negative, weak, moderate or marked, respectively. A final score ranging from 0 to 12 was obtained by multiplying the scores from each sample. Based on their final scores, the tumors were categorized as having low $(\leq 6)$ or high $(\geq 8)$ expression of OSR1 and ER $(26,27)$.

Cell culture and transfection. The human MCF-7 and MDA-MB-231 breast cancer cell lines were purchased from American Type Culture Collection. The MCF-7 cells were cultured in Dulbecco's modified Eagle's medium (DMEM) and the MDA-MB-231 cells were cultured in Leibovitz 15 Medium (L15), both supplemented with 10\% FBS (all from Thermo Fisher Scientific, Inc.) in an atmosphere of $5 \% \mathrm{CO}_{2}$ and at $37^{\circ} \mathrm{C}$. The cells were cultured in sterile culture dishes and passaged every 1 or 2 days using $0.25 \%$ trypsin (Thermo Fisher Scientific, Inc.).

For transfection, cells were seeded in a 6-well plate $24 \mathrm{~h}$ at $37^{\circ} \mathrm{C}$ prior to the experiment. The empty control vector, pCMV6, and pCMV6-OSRl plasmids were purchased from OriGene Technologies, Inc. The control siRNA and siRNA against OSRI (OSRl-siRNA) were synthesized by Guangzhou RiboBio Co., Ltd). The plasmids $(2.5 \mu \mathrm{g})$ were transfected into cells when density of treated cells reached $80-90 \%$, and the siRNAs $(5 \mathrm{nM})$ were transfected into cells when the density of treated cells was 40-50\% using Lipofectamine ${ }^{\circledR} 3000$ (Thermo Fisher Scientific, Inc.), according to the manufacturer's instructions.

Western blot analysis. Total protein from cells and tissue was extracted from cells using a cell lysis buffer (Thermo Fisher Scientific, Inc.) and quantified using the Bradford 
method. A total of $60 \mu \mathrm{g}$ total protein was separated using $10 \%$ SDS-PAGE, then transferred to a PVDF membrane (EMD Millipore; Merck KGaA). Following blocking with $5 \%$ skimmed milk at room temperature for $2 \mathrm{~h}$, membranes were incubated overnight at $4^{\circ} \mathrm{C}$ with antibodies against OSR1 (cat. no. sc-376545; 1:150; Santa Cruz Biotechnology, Inc.), $\beta$-catenin (sc-7963,1:100; Santa Cruz Biotechnology, Inc.), cyclin D1 (cat. no. sc-8396; 1:100; Santa Cruz Biotechnology, Inc.), c-Myc (cat. no. 554002; 1:200; BD Biosciences), axin (cat. no. sc-518090; 1:100; Santa Cruz Biotechnology, Inc.), Snail (cat. no. 3879,1:500; Cell Signaling Technology, Inc.), transcription factor 4 (TCF4; cat. no. sc-166699, 1:100; Santa Cruz Biotechnology, Inc.), E-cadherin (cat. no. 14472; 1:500; Cell Signaling Technology, Inc.), lymphoid enhancer-binding factor 1 (LEF1; cat. no. sc-374522; 1:100; Santa Cruz Biotechnology, Inc.), N-cadherin (cat. no. 13116; 1:500; Cell Signaling Technology, Inc.), $\beta$-actin (cat. no. sc-8432; 1:1,000; Santa Cruz Biotechnology,Inc.) and GAPDH (s cat.no.c-47724; 1:2,000; Santa Cruz Biotechnology, Inc.). Following washing in TBST for $15 \mathrm{~min}$, the membranes were incubated with horseradish peroxidase-conjugated anti-mouse/rabbit IgG secondary antibody (cat. no. SA00001-1/2; 1:2,000; ProteinTech Group, Inc.) at $37^{\circ} \mathrm{C}$ for $2 \mathrm{~h}$. Protein bands were visualized using an ECL kit (Thermo Fisher Scientific, Inc.) and detected with a bioimaging system (DNR Bio-Imaging Systems, Ltd.). The relative protein levels were calculated using $\beta$-actin or GAPDH as the loading control. The bands were quantified with Image J software (X64; National Institutes of Health).

Cell proliferation assay. Cells ( $3-4 \times 10^{3}$ cells/well) were plated in 96 -well plates at $37^{\circ} \mathrm{C}$ for $24 \mathrm{~h}$ following transfection and cultured in medium containing $10 \%$ fetal bovine serum. Cell Counting Kit-8 (CCK-8; Dojindo Molecular Technologies, Inc.) reagent was added to each well at $1: 10(\mathrm{v} / \mathrm{v})$ per $100 \mu \mathrm{l}$ and the cells were incubated for $2 \mathrm{~h}$ at $37^{\circ} \mathrm{C}$ according to the manufacturers' instructions. Cell proliferation results were detected using spectrophotometric quantitate on at $450 \mathrm{~nm}$.

Matrigel invasion assay. To assess the invasive ability of the transfected cells, Matrigel ${ }^{\mathrm{TM}}$ (BD Biosciences) and Transwell ${ }^{\circledR}$ chambers (Costar; Corning, Inc.) with a pore size of $8 \mu \mathrm{m}$ were used, according to the manufacturers' instructions. Briefly, $100 \mu \mathrm{l}$ Matrigel $^{\mathrm{TM}}$ (1:7 dilution) was added to each insert and the chambers were placed at $37^{\circ} \mathrm{C}$, for at least $2 \mathrm{~h}$. Then, $8 \times 10^{4}$ cells in $100 \mu 1$ medium supplemented with $2 \%$ FBS were added to the upper chamber. Medium supplemented with $20 \%$ FBS was added to the lower chamber as the chemoattractant. After $20 \mathrm{~h}$ of incubation, the filters were fixed at room temperature for $20 \mathrm{~min}$ and stained with hematoxylin at room temperature for $10 \mathrm{~min}$. The non-invading cells on the upper surface were removed with a cotton swab. The number of invasive cells in 10 high-power fields randomly was counted under an inverted microscope (magnification, x200). The experiments were performed in triplicate.

Statistical analysis. Data are expressed as the mean \pm standard deviation of three independent experiments. Unpaired Student's t-test was used to compare the mean values between two experimental groups. Paired Student's t-test was used to compare the mean expression levels of OSR 1 in tumor vs. adjacent non-tumor samples of the same individuals. The Kaplan-Meier curve was used to analyze the prognosis value of OSR1 in breast cancer from the online database The Human Protein Atlas. Associations between OSR1 expression level and clinicopathological factors were examined using the $\chi^{2}$ test. All statistical analyses were performed using GraphPad Prism v6.0 software (GraphPad Software, Inc.) and SPSS v17.0 software (SPSS, Inc.). $\mathrm{P}<0.05$ was considered to indicate a statistically significant difference.

\section{Results}

OSR1 expression is downregulated in breast cancer tissue, and is negatively associated with lymph node metastases, ER expression, and poor survival. The expression level of OSR 1 was examined in 70 pairs of breast cancer and adjacent normal breast tissue using immunohistochemistry. In normal breast tissue, 55 cases $(78.6 \%)$ demonstrated high expression levels of OSR1 (Fig. 1A) and 15 cases (21.4\%) demonstrated low expression levels. However, in breast cancer tissue, 30 cases $(42.9 \%)$ had high expression levels of OSR1 (Fig. 1B), whereas 40 cases (57.1\%) had low levels (Fig. 1C). The expression level of OSR 1 was lower in breast cancer tissue compared with that in normal breast tissue $(\mathrm{P}<0.001$; Table I). The low expression level of OSR1 in breast cancer was also significantly associated with lymph node metastases $(\mathrm{P}=0.004)$ and ER expression $(\mathrm{P}=0.031$; Fig. 1D). However, the expression level of OSR1 was not significantly associated with patient age $(\mathrm{P}=0.266)$, maximum diameter of the tumor $(\mathrm{P}=0.785)$, histological classification $(\mathrm{P}=0.554)$, TNM stage $(\mathrm{P}=0.165)$, $\mathrm{PR}$ expression $(\mathrm{P}=0.436)$ or HER2 expression $(\mathrm{P}=0.095$; Table I).

It was also confirmed that the expression level of OSR1 was significantly higher in normal breast tissue compared with that in breast cancer tissue, using western blot analysis $(2.12 \pm 0.18$ vs. $0.97 \pm 0.15 ; \mathrm{n}=20 ; \mathrm{P}<0.01$; Fig. $1 \mathrm{E}$ and $\mathrm{F})$. The significant reduction of OSR1 mRNA expression levels in breast cancer tissue was confirmed using the UALCAN web resource, based on the TCGA database $(\mathrm{P}<0.001$; Fig. S1A).

In addition, a search of the online database The Human Protein Atlas revealed that patients with breast cancer and low expression levels of OSR1 had significantly shorter overall survival rates compared with patients with high expression levels $(\mathrm{P}<0.01$; Fig. SIB).

OSR1 regulates the expression level of proteins in the Wnt signaling pathway and inhibits the proliferation of breast cancer cells. The expression level of OSR1 was low in MCF-7 cells and high in MDA-MB-231 cells; therefore, for a more appropriate comparison and visualization of the effects of OSR1, the OSR1 gene was overexpressed in MCF-7 cells (MCF7-OSR1), while OSR1 expression was knocked down in MDA-MB-231 cells (MDA-MB-231-siOSR1).

Compared with that in the control cells, the protein expression levels of $\beta$-catenin and the Wnt target genes, cyclin D1 and c-Myc were significantly decreased in MCF7-OSRl cells $(\mathrm{P}<0.05)$, whereas there was no significant difference in the protein expression levels of axin, TCF4 and LEF1 ( $P>0.05$; Fig. 2A). By contrast, compared with that in the control cells, the protein expression level of $\beta$-catenin, cyclin D1 and c-Myc 
A

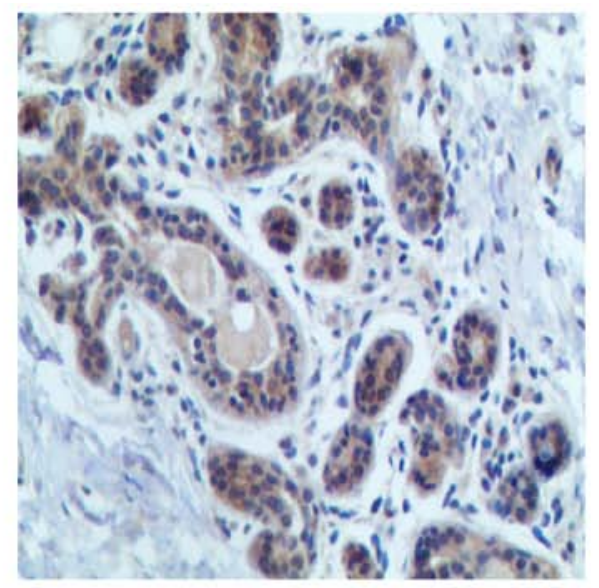

C

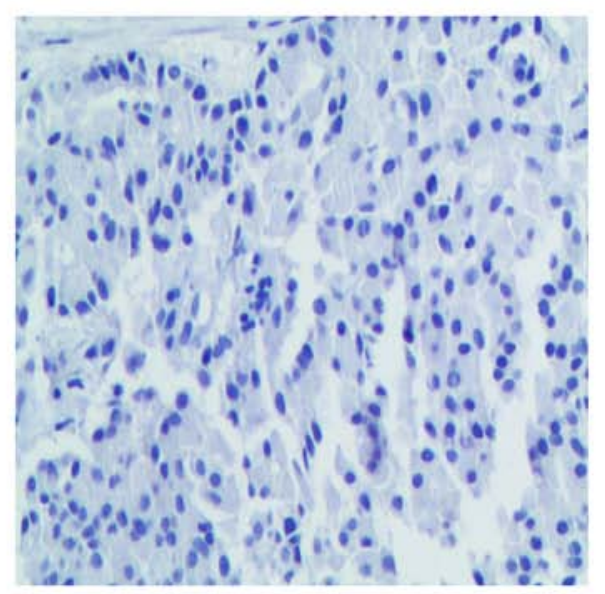

E

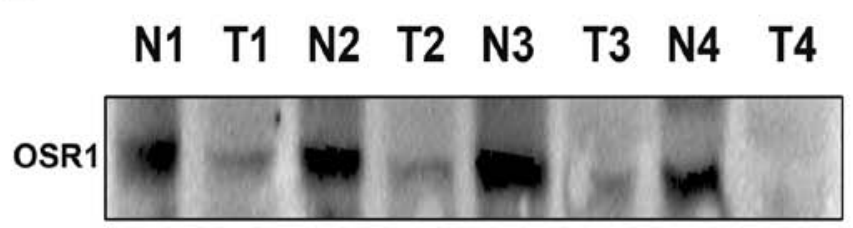

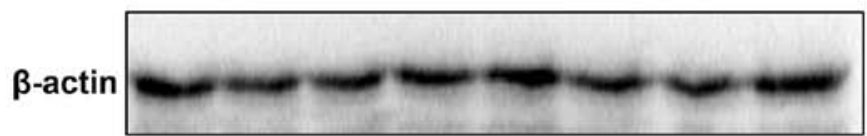

B

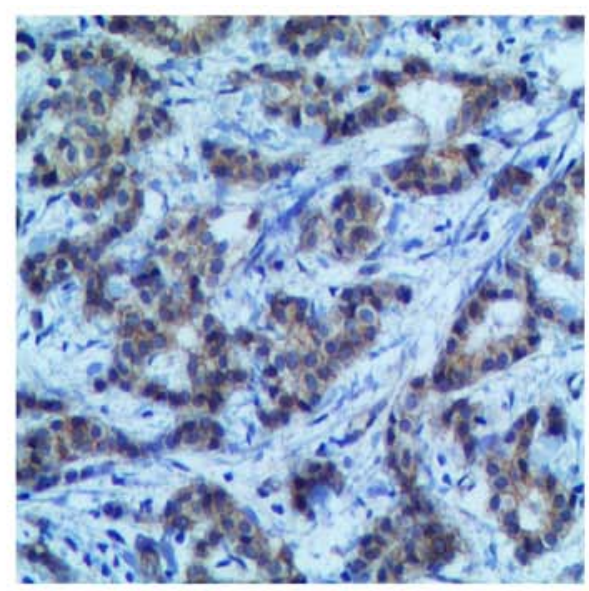

D

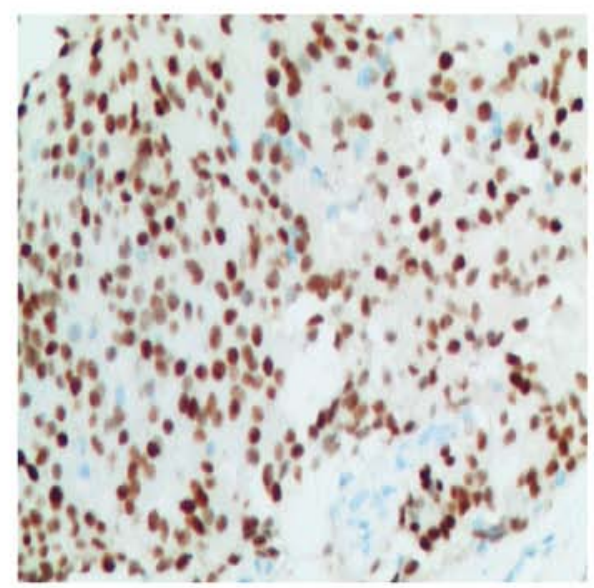

F

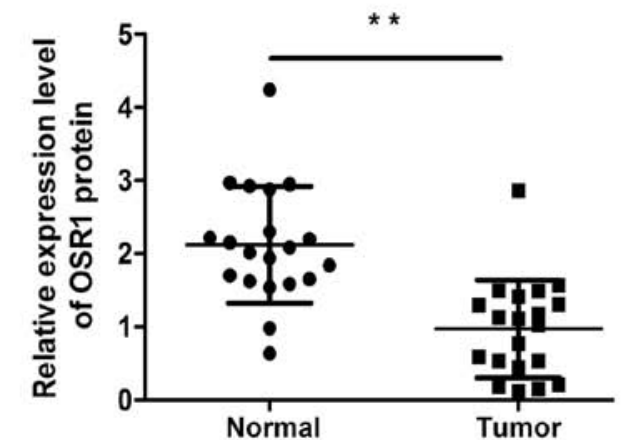

Figure 1. Immunohistochemistry staining and expression of OSR1 and ER in breast cancer and normal breast tissue. (A) High expression of OSR1 in a normal mammary gland. (B) High expression of OSR1 in breast cancer tissue. A breast cancer tissue demonstrating (C) low expression of OSR1 and (D) positive expression of ER. (E) Western blot analysis of OSR1 in breast cancer tissue and in adjacent normal breast tissue. $\beta$-actin served as an internal control. (F) The relative protein expression level of OSR1 in breast cancer and adjacent normal breast tissue $(n=20)$. Magnification, $x 200 .{ }^{* *} \mathrm{P}<0.01$. OSR1, odd-skipped related transcription factor 1; ER, estrogen receptor; $\mathrm{N}$, adjacent normal breast tissue; $\mathrm{C}$, breast cancer tissue.

was significantly increased in MDA-MB-231-siOSR1 cells $(\mathrm{P}<0.05)$, whereas there was no significant difference in the expression levels of axin, TCF4 and LEF1 ( $P>0.05$; Fig. 2B). In addition, overexpression of OSR1 significantly inhibited proliferation of MCF-7 cells from day two $(\mathrm{P}<0.05$; Fig. 2C) and downregulation of OSR1 significantly increased proliferation of MDA-MB-231 cells from day two $(\mathrm{P}<0.05$; Fig. 2D).

OSR1 regulates the expression of EMT-related proteins and inhibits the invasive ability of breast cancer cells. Overexpression of OSR1 significantly inhibited the invasive ability of MCF-7 cells $(\mathrm{P}<0.01)$, while downregulation of OSR1 promoted the invasive ability of MDA-MB-231 cells $(\mathrm{P}<0.01$; Fig. $3 \mathrm{~A}$ and $\mathrm{B})$.

Compared with that in the control cells, the expression level of E-cadherin in MCF7-OSR1 cells was significantly increased $(\mathrm{P}<0.01)$, whereas the expression levels of $\mathrm{N}$-cadherin and Snail were significantly decreased $(\mathrm{P}<0.05$; Fig. $3 \mathrm{C})$. By contrast, compared with that in the control cells, the expression level of E-cadherin in MDA-MB-231-siOSR1 cells was significantly decreased $(\mathrm{P}<0.01)$, whereas the expression levels of N-cadherin and Snail were significantly increased $(\mathrm{P}<0.05$; Fig. 3D). 
Table I. Association between OSR1 expression level and clinicopathological factors in breast cancer.

\begin{tabular}{|c|c|c|c|c|}
\hline \multirow[b]{2}{*}{ Clinicopathological factor } & \multirow[b]{2}{*}{ Number of patients } & \multicolumn{2}{|c|}{ OSR1 expression } & \multirow[b]{2}{*}{ P-value } \\
\hline & & High, n (\%) & Low, n (\%) & \\
\hline Tissue & & & & $<0.001$ \\
\hline Normal & 70 & 55 (78.6) & $15(21.4)$ & \\
\hline Breast cancer & 70 & $30(42.9)$ & $40(57.1)$ & \\
\hline Age, years & & & & 0.266 \\
\hline$<50$ & 31 & $11(35.5)$ & $20(64.5)$ & \\
\hline$\geq 50$ & 39 & $19(48.7)$ & $20(51.3)$ & \\
\hline Maximum diameter, $\mathrm{cm}$ & & & & 0.785 \\
\hline$\leq 2$ & 34 & $16(47.1)$ & $18(52.9)$ & \\
\hline $2-5$ & 26 & $10(38.5)$ & $16(61.5)$ & \\
\hline$>5$ & 10 & $4(40.0)$ & $6(60.0)$ & \\
\hline Histological classification & & & & 0.554 \\
\hline I & 18 & $8(44.4)$ & $10(55.6)$ & \\
\hline II & 44 & $20(45.5)$ & $24(54.5)$ & \\
\hline III & 8 & $2(25.0)$ & $6(75.0)$ & \\
\hline TNM stages & & & & 0.165 \\
\hline I-II & 53 & $21(39.6)$ & $32(60.4)$ & \\
\hline III-IV & 17 & $10(58.8)$ & 7 (41.2) & \\
\hline Lymphatic metastasis & & & & $0.004^{\mathrm{a}}$ \\
\hline Yes & 30 & $7(23.3)$ & $23(76.7)$ & \\
\hline No & 40 & $23(57.5)$ & $17(42.5)$ & \\
\hline ER expression & & & & $0.031^{\mathrm{b}}$ \\
\hline Positive & 45 & $15(33.3)$ & $30(66.7)$ & \\
\hline Negative & 25 & $15(60.0)$ & $10(40.0)$ & \\
\hline PR expression & & & & 0.436 \\
\hline Positive & 43 & $20(46.5)$ & $23(53.5)$ & \\
\hline Negative & 27 & $10(37.0)$ & $17(63.0)$ & \\
\hline HER-2 expression & & & & 0.095 \\
\hline Positive & 24 & $7(29.2)$ & $17(70.8)$ & \\
\hline Negative & 46 & $23(50.0)$ & $23(50.0)$ & \\
\hline
\end{tabular}

${ }^{\mathrm{a}} \mathrm{P}<0.01$; ${ }^{\mathrm{P}}<0.05$. OSR1, odd-skipped related 1; TNM, tumor-node-metastasis; ER, estrogen receptor; PR, progesterone receptor; HER-2, human epidermal growth factor receptor 2 .

\section{Discussion}

Previous studies on OSR1 were focused on the field of embryonic development (12-17), while the studies on OSR1 in tumors have been limited $(18,19)$. Therefore, the association between OSR1 and tumorigenesis, and the possible mechanisms, have not been discussed. The results of the present study demonstrated that the expression level of OSR1 was significantly reduced in breast cancer tissue compared with that in normal breast tissue and negatively associated with lymph node metastases and ER expression level. Therefore, reduced expression of OSR1 may be involved in the progression of breast cancer. Notably, the present study demonstrated negative association between ER expression and OSR1 in breast cancer. Thus, high level of ER may be involved in the downregulation of OSR1 expression and may be one of the potential reasons for low expression of OSR1; however, further investigation is required. To the best of our knowledge, this was the first time that the expression pattern and clinical significance of OSR1 in breast cancer was examined. Data from TCGA database confirmed that OSR1 expression is significantly reduced in breast cancer and associated with poor prognosis.

Furthermore, the in vitro experiments in the present study confirmed that overexpression of OSR 1 inhibited the proliferative and invasive abilities of breast cancer cells. Otani et al (19) demonstrated that OSR 1 suppresses the protein expression of cytoplasmic $\beta$-catenin, TCF- 1 and LEF1, which are part of the Wnt signaling pathway. OSR1 acts as a functional tumor suppressor through the transcriptional repression of TCF/LEF in gastric cancer (19). The present study demonstrated that overexpression of OSR 1 inhibited the expression of $\beta$-catenin and Wnt target genes, cyclin D1 and c-Myc, in breast cancer cells. 
A

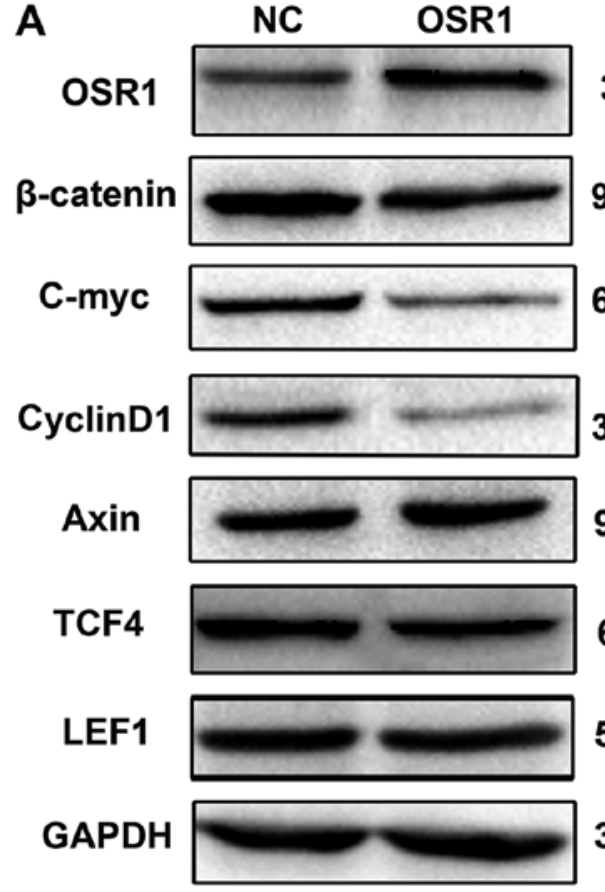

$30 \mathrm{kDa}$

$95 \mathrm{kDa}$

$60 \mathrm{kDa}$

$54 \mathrm{kDa}$

$36 \mathrm{kDa}$

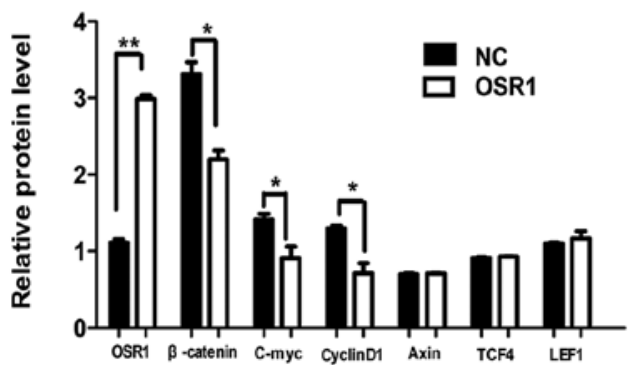

C

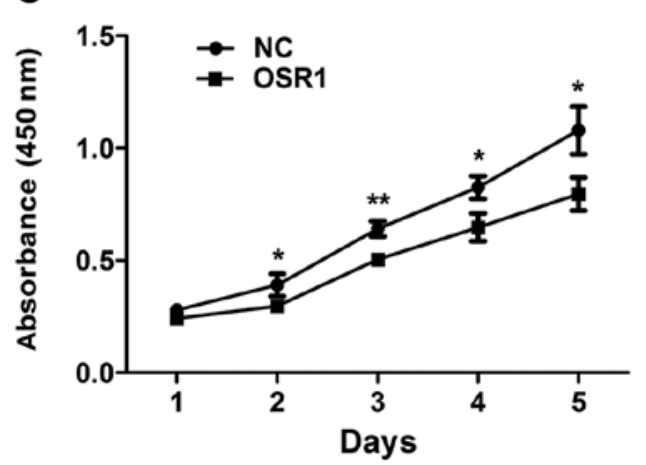

B

OSR1 SiNC SiOSR1

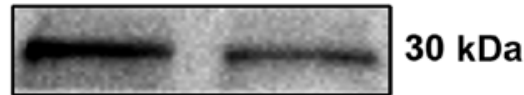

$\beta$-catenin

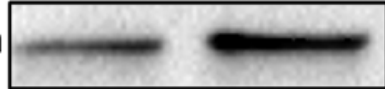

$92 \mathrm{kDa}$

C-myc

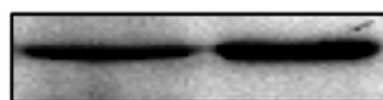

$62 \mathrm{kDa}$

CyclinD1

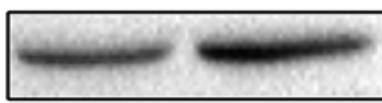

$30 \mathrm{kDa}$

Axin

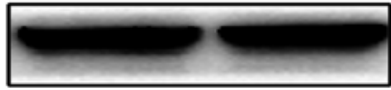

$95 \mathrm{kDa}$

TCF4

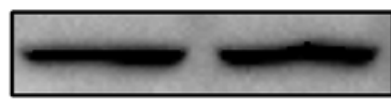

$60 \mathrm{kDa}$

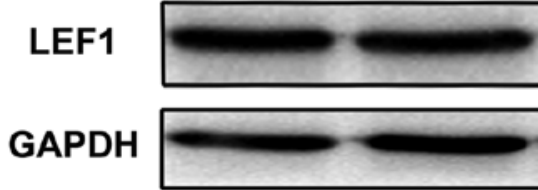

$54 \mathrm{kDa}$

$36 \mathrm{kDa}$

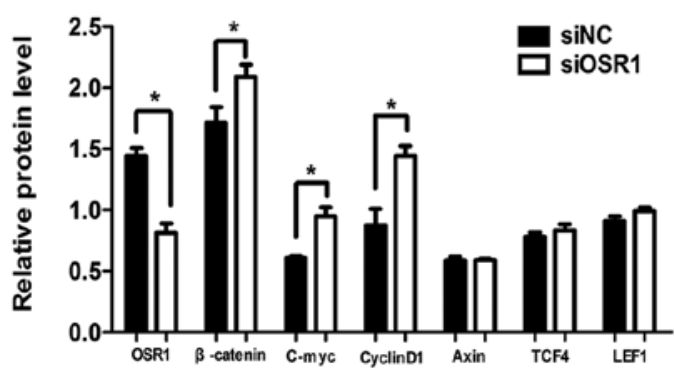

D

MDA-MB-231

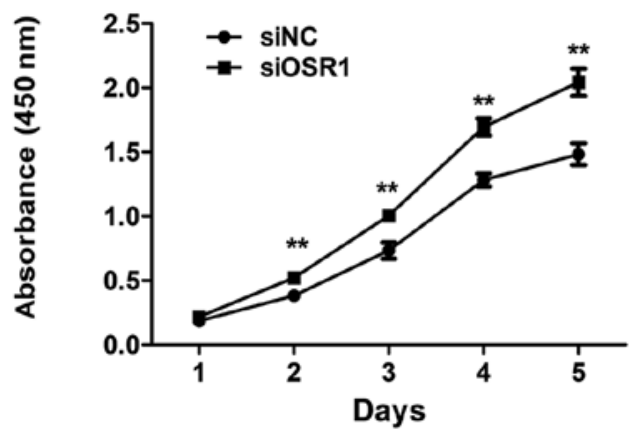

Figure 2. OSR1 inhibits the expression of Wnt target proteins and the proliferative abilities of breast cancer cells. Western blot analysis and relative protein levels for OSR1, $\beta$-catenin, c-Myc, cyclin D1, Axin, TCF4, and LEF1 in (A) MCF7-OSR1 and NC cells and (B) in MDA-MB-231 cells transfected with an OSR1 overexpression plasmid, siOSR1 or siNC. GAPDH served as an internal control. The cell growth curve of (C) MCF7 cells transfected with an OSR1 overexpression plasmid or its NC and (D) MDA-MB-231 cells transfected with siOSR1 or siNC. ${ }^{*} \mathrm{P}<0.05,{ }^{* *} \mathrm{P}<0.01$. OSR1, odd-skipped related transcription factor 1; TCF4, transcription factor 4; LEF1, lymphoid enhancer binding factor 1; NC, negative control; si, small interfering; siNC, scramble control siRNA.

As a cell cycle regulator, cyclin D1 is essential for progression through the $\mathrm{G}_{1}$ phase and is a candidate proto-oncogene (28). Mutation, amplification and overexpression of cyclin D1 has been found to alter cell cycle progression and may contribute to the proliferation of tumor cells $(29,30)$. As such, OSR1 inhibits the proliferative abilities of breast cancer cells by inhibiting the activity of the Wnt signaling pathway.

In addition, the results of the present study demonstrated that overexpression of OSR 1 inhibited the protein expression level of Snail. An integrated and complex signaling network of pathways, including Wnt, TGF- $\beta$, Notch and BMP, are known to activate Snail (31). As an EMT-inducing transcription factor, Snail has been found to regulate the protein expression of the cell adhesion molecules, E-cadherin and N-cadherin in the EMT process (31). The present study examined whether the protein expression levels of E-cadherin, $\mathrm{N}$-cadherin and Snail were altered through regulation of OSR1 and the results demonstrated that overexpression of OSR1 increased 
A

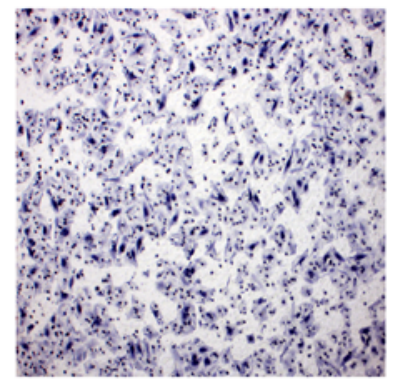

B siNC

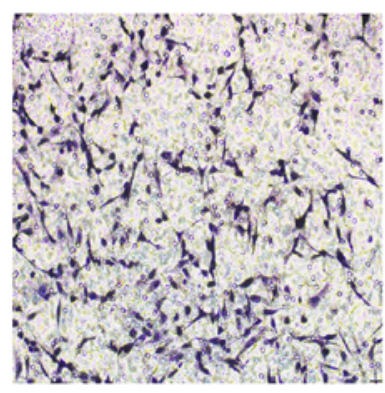

OSR1

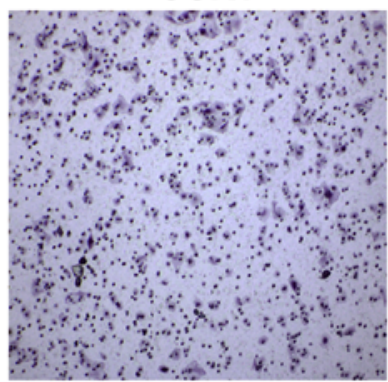

siOSR1

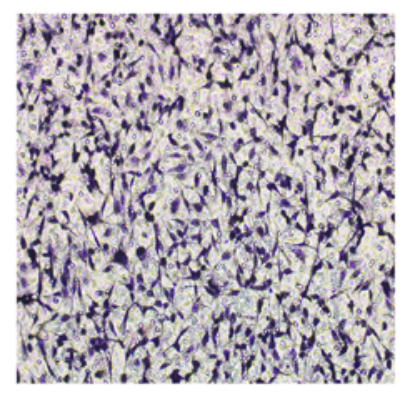

D
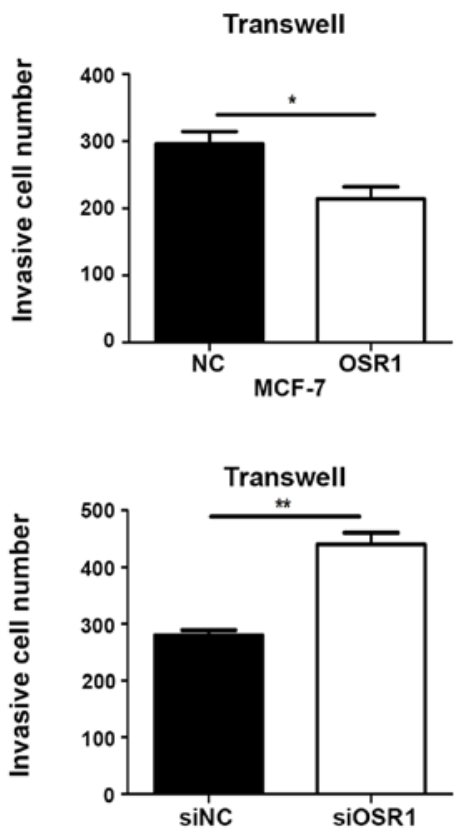

MDA-MB-231
C

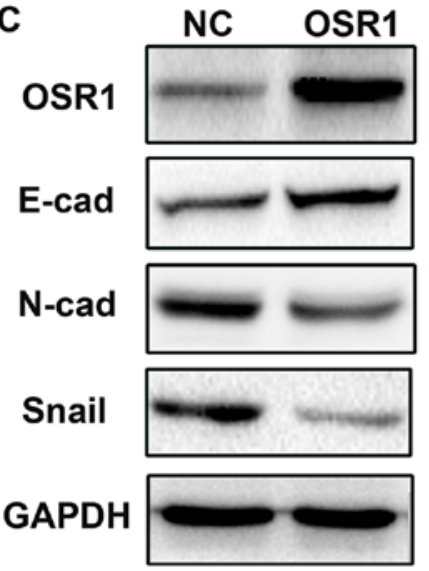

$30 \mathrm{kDa}$

135 kDa

140 kDa

29 kDa

36 kDa

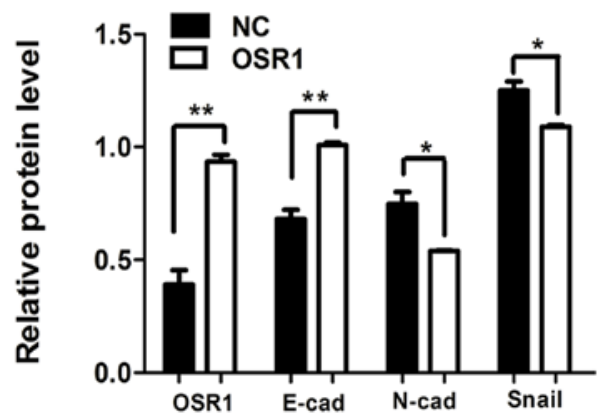

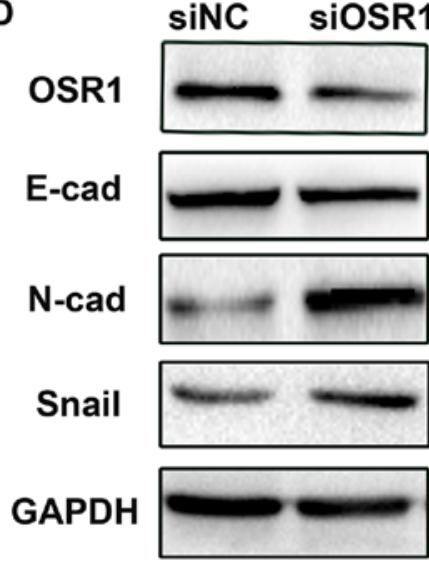

$30 \mathrm{kDa}$

135 kDa

140 kDa

29 kDa

$36 \mathrm{kDa}$

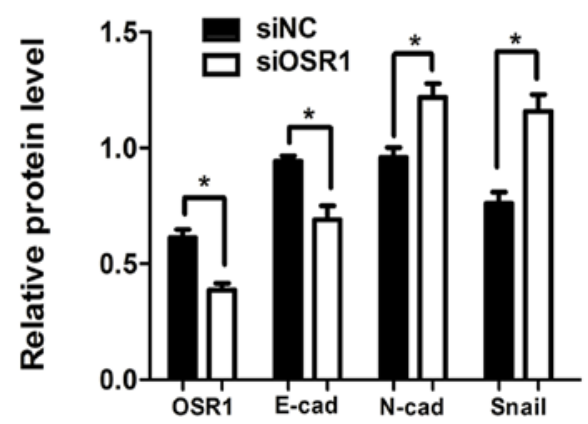

Figure 3. OSR 1 inhibits the invasive abilities and downregulates epithelial-mesenchymal transition -related proteins in breast cancer cells. Representative images of the Matrigel ${ }^{\mathrm{TM}}$ invasion assay and the invasive cell number for (A) MCF7 transfected with OSR1 overexpression plasmid or NC and (B) MDA-MB-231 cells transfected with siOSR1 or siNC. Western blot analysis and relative protein levels for OSR1, E-cadherin, N-cadherin and Snail in (C) MCF7 cells transfected with an OSR1 overexpression plasmid or its NC and (D) in MDA-MB-231 cells transfected with siOSR1 or siNC. GAPDH served as an internal control. ${ }^{*} \mathrm{P}<0.05,{ }^{* *} \mathrm{P}<0.01$. OSR1, odd-skipped related transcription factor 1; NC, negative control; si, small interfering; siNC, scramble control siRNA; cad-cadherin.

expression level of E-cadherin and decreased expression of $\mathrm{N}$-cadherin, thereby suppressing the EMT process in breast cancer cells. A previous study has suggested that the EMT process contributes to early stage dissemination of cancer cells and is important for invasion and metastasis (32). Thus, OSR1 may inhibit the invasive abilities of breast cancer cells by restricting the EMT process. Apart from the Wnt signaling pathway and EMT, there may be other pathways involved in the regulating mechanism of OSR1, which will be investigated in future studies. In addition, the lack of a normal breast cell line as a normal control is also a limitation to the present study, while, in vivo tumorigenicity assay is also required to further confirm the function of OSR1, which will be performed in the future. 
In conclusion, OSR1 is a novel tumor suppressor gene, which is downregulated in breast cancer tissue, which suggests it could be a potential marker for tumor malignancy and prognosis, as well as a possible target for drug treatment. OSR1 downregulates the invasive and proliferative abilities of breast cancer by suppressing the EMT process and activity of the Wnt signaling pathway.

\section{Acknowledgements}

Not applicable.

\section{Funding}

This study was supported by the Program for Liaoning Excellent Talents in University (grant no. LR2015067), the Program for The Doctoral Scientific Research Foundation of Liaoning Province (grant no. 2019-BS-094) and the Natural Science Foundation Funding Scheme of Liaoning Province (grant no. 2019-MS-145).

\section{Availability of data and materials}

The datasets used and/or analyzed during the present study are available from the corresponding author on reasonable request.

\section{Authors' contributions}

HX and YW conceived and designed the experiments. YW performed some experiments, analyzed the data and wrote the manuscript. LL and FX performed some experiments and analyzed the data. All authors read and approved the final manuscript.

\section{Ethics approval and consent to participate}

The study was approved by the Institutional Review Board of the First Hospital and College of Basic Medical Sciences of China Medical University [approval no. iLS(2018)016]. Written informed consent was obtained from all patients.

\section{Patient consent for publication}

Not applicable.

\section{Competing interests}

The authors declare that they have no competing interests.

\section{References}

1. Cadoo KA, Fornier MN and Morris PG: Biological subtypes of breast cancer: Current concepts and implications for recurrence patterns. Q J Nucl Med Mol Imaging 57: 312-321, 2013.

2. Yip $\mathrm{CH}$ and Rhodes A: Estrogen and progesterone receptors in breast cancer. Future Oncol 10: 2293-2301, 2014.

3. Fidler IJ and Kripke ML: Genomic analysis of primary tumors does not address the prevalence of metastatic cells in the population. Nat Genet 34: 23, 2003.

4. Cedolini C, Bertozzi S, Londero AP, Bernardi S, Seriau L, Concina S, Cattin F and Risaliti A: Type of breast cancer diagnosis, screening, and survival. Clin Breast Cancer 14: 235-240, 2014.
5. Carey LA, Perou CM, Livasy CA, Dressler LG, Cowan D, Conway K, Karaca G, Troester MA, Tse CK, Edmiston S, et al: Race, breast cancer subtypes, and survival in the carolina breast cancer study. JAMA 295: 2492-2502, 2006.

6. McNamara KM, Moore NL, Hickey TE, Sasano H and Tilley WD: Complexities of androgen receptor signalling in breast cancer. Endocr Relat Cancer 21: T161-T181, 2014.

7. Katoh M: Molecular cloning and characterization of OSR 1 on human chromosome 2p24. Int J Mol Med 10: 221-225, 2002.

8. James RG and Schultheiss TM: Bmp signaling promotes intermediate mesoderm gene expression in a dose-dependent, cell-autonomous and translation-dependent manner. Dev Biol 288: 113-125, 2005.

9. Mae S, Shirasawa S, Yoshie S, Sato F, Kanoh Y, Ichikawa H, Yokoyama T, Yue F, Tomotsune D and Sasaki K: Combination of small molecules enhances differentiation of mouse embryonic stem cells into intermediate mesoderm through BMP7-positive cells. Biochem Biophys Res Commun 393: 877-882, 2010.

10. Verlinden L, Kriebitzsch C, Eelen G, Camp MV, Leyssens C, Tan BK, Beullens I and Verstuyf A: The odd-skipped related genes Osr1 and Osr2 are induced by 1,25-dihydroxyvitamin D3. J Steroid Biochem Mol Biol 136: 94-97, 2013.

11. Yamauchi M, Kawai S, Kato T, Ooshima T and Amano A: Odd-skipped related 1 gene expression is regulated by Runx2 and Ikzf1 transcription factors. Gene 426: 81-90, 2008.

12. Terashima AV, Mudumana SP and Drummond IA: Odd skipped related 1 is a negative feedback regulator of nodal-induced endoderm development. Dev Dyn 243: 1571-1580, 2014.

13. Liu H, Lan Y, Xu J, Chang CF, Brugmann SA and Jiang R: Odd-skipped related-1 controls neural crest chondrogenesis during tongue development. Proc Natl Acad Sci USA 110: 18555-18560, 2013.

14. Wang Q, Lan Y, Cho ES, Maltby KM and Jiang R: Odd-skipped related 1 (Odd 1) is an essential regulator of heart and urogenital development. Dev Biol 288: 582-594, 2005.

15. Tena JJ, Neto A, de la Calle-Mustienes E, Bras-Pereira C, Casares F and Gómez-Skarmeta JL: Odd-skipped genes encode repressors that control kidney development. Dev Biol 301: 518-531, 2007.

16. Stricker S, Mathia S, Haupt J, Seemann P, Meier J and Mundlos S: Odd-skipped related genes regulate differentiation of embryonic limb mesenchyme and bone marrow mesenchymal stromal cells. Stem Cells Dev 21: 623-633, 2012.

17. James RG, Kamei CN, Wang Q, Jiang R and Schultheiss TM: Odd-skipped related 1 is required for development of the metanephric kidney and regulates formation and differentiation of kidney precursor cells. Development 133: 2995-3004, 2006.

18. Zhang Y, Yuan Y, Liang P, Guo X, Ying Y, Shu XS, Gao M Jr and Cheng Y: OSR1 is a novel epigenetic silenced tumor suppressor regulating invasion and proliferation in renal cell carcinoma. Oncotarget 8: 30008-30018, 2017.

19. Otani K, Dong Y, Li X, Lu J, Zhang N, Xu L, Go MYY, Ng EKW, Arakawa T, Chan FKL, et al: Odd-skipped related 1 is a novel tumour suppressor gene and a potential prognostic biomarker in gastric cancer. J Pathol 234: 302-315, 2014

20. Xie XM, Zhang ZY, Yang LH, Yang DL, Tang N, Zhao HY, $\mathrm{Xu}$ HT, Li QC and Wang EH: Aberrant hypermethylation and reduced expression of disabled-2 promote the development of lung cancers. Int J Oncol 43: 1636-1642, 2013.

21. Xu HT, Yang LH, Li QC, Liu SL, Liu D, Xie XM and Wang EH: Disabled-2 and Axin are concurrently colocalized and underexpressed in lung cancers. Hum Pathol 42: 1491-1498, 2011.

22. Allison KH, Brogi E, Ellis LO, et al: WHO Classification of Tumours of Breast Tumors. 5th ed. IARC, Lyon, France, 2019.

23. Gabriel NH, Stephen BE and Armando G: New and important changes in the TNM staging system for breast cancer. Am Soc Clin Oncol Educ Book 38: 457-467, 2018.

24. Chandrashekar DS, Bashel B, Balasubramanya $\mathrm{SAH}$ Creighton CJ, Ponce-Rodriguez I, Chakravarthi BVSK and Varambally S: UALCAN: A portal for facilitating tumor subgroup gene expression and survival analyses. Neoplasia 19: 649-658, 2017.

25. Uhlen M, Zhang C, Lee S, Sjöstedt E, Fagerberg L, Bidkhori G, Benfeitas R, Arif M, Liu Z, Edfors F, et al: A pathology atlas of the human cancer transcriptome. Science 357: eaan2507, 2017.

26. Wang Y, Lei L, Zheng YW, Zhang L, Li ZH, Shen HY, Jiang GY, Zhang XP, Wang EH and Xu HT: Odd-skipped related 1 inhibits lung cancer proliferation and invasion by reducing Wnt signaling through the suppression of SOX9 and $\beta$-catenin. Cancer Sci 109: 1799-1810, 2018. 
27. Zheng YW, Zhang L, Wang Y, Chen SY, Lei L, Tang N, Yang DL, Bai LL,Zhang XP,Jiang GY, et al: Thyroid cancer 1 (C8orf4) shows high expression, no mutation and reduced methylation level in lung cancers, and its expression correlates with $\beta$-catenin and DNMT1 expression and poor prognosis. Oncotarget 8: 62880-62890, 2017.

28. Wang Y, Zhu JF, Liu YY and Han GP: An analysis of cyclin D1, cytokeratin 5/6 and cytokeratin $8 / 18$ expression in breast papillomas and papillary carcinomas. Diagn Pathol 8: 8, 2013.

29. Horvai AE, Kramer MJ and O'Donnell R: Beta-catenin nuclear expression correlates with cyclin D1 expression in primary and metastatic synovial sarcoma: A tissue microarray study. Arch Pathol Lab Med 130: 792-798, 2006.

30. Lin L, Hicks D, Xu B, Sigel JE, Bergfeld WF, Montgomery E, Fisher C, Hartke M, Tubbs R and Goldblum JR: Expression profile and molecular genetic regulation of cyclin D1 expression in epithelioid sarcoma. Mod Pathol 18: 705-709, 2005.
31. Wang Y, Shi J, Chai K, Ying X and Zhou BP: The Role of snail in EMT and tumorigenesis. Curr Cancer Drug Targets 13: 963-972, 2013.

32. Zheng X, Carstens JL, Kim J, Scheible M, Kaye J, Sugimoto H, Wu CC, LeBleu VS and Kalluri R: Epithelial-to-mesenchymal transition is dispensable for metastasis but induces chemoresistance in pancreatic cancer. Nature 527: 525-530, 2015

(1) (9)

This work is licensed under a Creative Commons Attribution-NonCommercial-NoDerivatives 4.0 International (CC BY-NC-ND 4.0) License. 